\title{
ANALISIS MARKETING MIX TERHADAP KEPUTUSAN PEMBELIAN KONSUMEN PT. LG ELEKTONIK DI BANDAR LAMPUNG
}

\author{
Nelson $^{(1)^{*}}$, Kuswarak $^{(2)}$, Renopka $^{(3)}$ \\ Universitas Sang Bumi Ruwa Jurai \\ nelson@fe.saburai.ac.id,kuswarak@fe.saburai.ac.id,renopka@gmail.com
}

\begin{abstract}
Abstrak. Masalah dalam penelitian ini Masih ada isu tentang kualitas marketing mix dalam pembelian elektronik LG yang menyangkut keamanan dan kenyamanan konsumen, Masih banyak konsumen yang kurang percaya akan nilai dan manfaat dari marketing mix produk elektronik LG.Tujuan penelitian ini Untuk mengetahui pengaruh marketing mix terhadap keputusan pembelian konsumen di PT Elektronik di Bandar Lampung. Metode yang digunakan dalam penelitian ini menggunakan deskriptif kuantatif dengan analisis data menggunakan regresi liniear sederhana menggunakan 40 konsumen sebagai sampel. Teknik pengumpulan data yang digunakan adalah observasi, wawancara, kuisioner dan studi dokumen. Berdasarkan penelitian yang dilakukan menunjukkan Variabel marketing mix mempengaruhi keputusan pembelian. Hal ini dilihat dalam analisis regresi linear sederhana dengan rumus $\mathrm{y}=\mathrm{a}+\mathrm{bx}$ yang telah dilakukan menunjukkan sebesar 0,963 , ini artinya bahwa variabel keputusan pembelian dapat dijelaskan oleh marketing mix sebesar $92 \%$ sedangkan sisanya $(100 \%-92 \%=8 \%)$.
\end{abstract}

Kata Kunci: Marketing Mix, Keputusan Pembelian

\section{PENDAHULUAN}

Di era globalisasi ini banyak sekali terdapat merk-merk elektronik yang ditawarkan kepada konsumen seperti merk SAMSUNG, SHARP, LG, PANASONIK, SONY dan lain sebagainya. Dimana masingmasing merk Elektronik tersebut berusaha untuk membuat produknya lebih unggul dibandingkan merk lain maka, kegiatan pemasaran yang baik dan tepatlah yang memegang peranan yang penting dalam menunjang kelangsungan usaha dan perkembangan suatu perusahaan. Dengan kata lain pihak produsen harus mampu merebut hati konsumen akan hasil suatu produksi yang dijual dan berupaya untuk memuaskan konsumennya.

Dalam memahami perilaku konsumen tentu tidak mudah karena konsumen memiliki sifat yang berbeda-beda sebagaimana dari kebutuhan manusia yang tidak terbatas disamping dipengaruhi oleh kondisi eksternal dan internal lainnya yang berakibat langsung terhadap prilaku konsumen. Faktor eksternal tersebut meliputi, kebudayaan, sub budaya, kelas sosial, kelompok sosial, kelompok referensi, dan keluarga. Sedangkan faktor internalnya adalah faktor yang ada pada diri konsumen itu sendiri ( psikologis ) yang meliputi : belajar, kepribadian, dan konsep diri, serta sikap.

Oleh sebab itu, konsumen harus dapat mengendalikan perubahan prilaku tersebut dengan berusaha mengimbanginya, yakni dengan mempengaruhi konsumen dalam membeli produk yang ditawarkan dan melalui evaluasi berkala demi kelangsungan hidup produsen itu sendiri. Tidak semua Elektronik diminati oleh sebagian besar konsumen yang ada, tetapi hanya beberapa saja. Melihat keadaan ini penulis tertarik untuk melakukan penelitian mengenai perilaku konsumen yang yang merupakan salah satu dasar dalam menerapkan strategi pemasaran untuk mencapai tujuan, yaitu memberikan kepuasan kepada konsumen,sehingga diharapkan dapat membawa kepada peningkatan penjualan 
yang berakibat langsung pada peningkatan pasar.

Keputusan pembelian adalah tindakan yang dilakukan konsumen untuk melakukan pembelian sebuah produk. Oleh karena itu, pengambilan keputusan pembelian konsumen merupakan suatu proses pemilihan salah satu dari beberapa alternatif penyelesaian masalah dengan tindak lanjut yang nyata.(Harahap, 2017). Adapun yang menjadi faktor-faktor keputusan pembelian yang dipertimbangkan peneliti adalah lokasi, kelengkapan produk dan harga. Lokasi merupakan salah satu faktor penentu kesuksesan sebuah usaha karena mempengaruhi biaya usaha. Lokasi usaha harus dipertimbangkan dengan sebaik mungkin. Jika perusahaan salah dalam memilih lokasi, maka perusahaan akan menanggung resiko berupa kerugian atau tidak tercapai sasaran dan tujuan yang diinginkan oleh perusahaan.

Menurut Setiadi (2003), pengambilan keputusan yang diambil oleh seseorang dapat disebut sebagai suatu pemecahan masalah. Dalam proses pengambilan keputusan, konsumen memiliki sasaran atau perilaku yang ingin dicapai atau dipuaskan. Selanjutnya konsumen membuat keputusan perilaku mana yang ingin dilakukan untuk mencapai sasaran tersebut.(Kusumawardani, 2011)

Menurut Setiadi dalam Nofri dan Hafifah untuk memahami konsumen dan mengembangkan strategi pemasaran yang tepat, kita harus memahami apa yang mereka pikirkan (kognisi) dan mereka rasakan (afeksi), apa yang mereka lakukan (perilaku), dan serta dimana (kejadian disekitar) yang mempengaruhi serta dipengaruhi oleh apa yang dipikirkan, dirasakan, dan dilakukan konsumen tersebut.(Nofri \& Hafifah, 2018)

Menurut Kotler dalam Poluan Bauran Pemasaran Atau Marketing Mix adalah seperangkat alat pemasaran yang digunakan perusahaan untuk mencapai tujuan pemasarannya di pasar sasaran . McCarthy dalam Kotler dan Keller dalam Poluan mengklasifikasikan aktivitas-aktivitas ini sebagai sarana atau alat bauran pemasaran dari empat jenis yang luas disebut dengan 4P dari pemsaran yaitu : Produk (Product), Harga (Price), Promosi (Promotion), dan Tempat/Distribusi (Placel Distribution). (Poluan et al., 2019)

Pada dasarnya keberhasilan usaha ritel terletak pada penyediaan produk yang dibutuhkan sehari-hari, baik secara kualitas maupun kuantitas serta harga yang terjangkau terutama bagi masyarakat berpenghasilan sedang. Untuk melakukan persaingan di wilayah tempatnya berada, PT LG Eletronik Bandar Lampung akan melakukan strategi pemasaran. Dari segi harga dan promosi PT LG Eletronik Bandar Lampung mengadakan potongan dengan harga yang menarik sehingga mampu menarik para konsumen untuk memutuskan melakukan pembelian. Lokasinya pun sangat strategis yaitu di pinggir jalan sehingga mudah ditempuh dengan transportasi apapun termasuk menggunakan angkutan umum.

Memilih tempat belanja adalah proses interaksi antara strategi pemasaran peritel dan karakteristik individual dan situasional dari pembeli. Untuk itu pemasar harus mengenali kebutuhan dan keinginan konsumen yang mendorong konsumen memilih atau tidak memilih, memutuskan membeli atau tidak membeli suatu produk tertentu adalah penting. Bagaimana produsen mampu menciptakan produk yang dapat memuaskan konsumennya apabila dia tidak tahu keinginan dan kebutuhan konsumen untuk memutuskan membeli suatu produk.

Maka dalam pemasaran, bauran pemasaran atau marketing mix sangatlah 
dibutuhkan. Marketing mix ini terdiri dari produk, harga, lokasi ,promosi, konsumen, proses dan tampilan fisik lokasi. Dalam mendesain produk, menetapkan harga, penempatan/lokasi, dan dalam melakukan promosi.

Upaya meneliti perilaku konsumen perlu dilakukan karena pemahaman terhadap perilaku konsumen merupakan kunci keberhasilan strategi pemasaran. Melalui pemahaman perilaku konsumen, pihak manajemen perusahaan dapat menyusun strategi dan program yang tepat dalam rangka memanfaatkan peluang yang ada dan mengungguli para pesaingnya. Perilaku konsumen sendiri merupakan tindakan-tindakan individu yang secara langsung terlibat dalam usaha memperoleh, menggunakan, dan menentukan produk dan jasa termasuk proses pengambilan keputusan yang mendahului dan mengikuti tindakan-tindakan tersebut.

Berdasarkan penelitian sebelumnya tentang Strategi pengembangan pada agroindustri Kopi Bubuk Cap Intan di Kota Bandar Lampung, yaitu : (a) pemilik agroindustri menentukan kebijakan dalam memanfaatkan teknologi yang digunakan, (b) memanfaatkan lokasi yang berada di pasar dan terus bekerjasama dengan PTPN 7 sehingga dapat memiliki peluang yang lebih besar dibandingkan pesaing, (c) meningkatkan(Ledy et al., 2019) kualitas produk yang dihasilkan agar mendapatkan keuntungan maksimal sehingga perkembangan teknologi dapat di ikuti, (d) Mempertahankan kualitas produk yang baik agar produk tetap dapat bersaing dengan pelaku usaha sejenis yang masuk ke pasar, (e) memberdayakan kemampuan dan keterampilan SDM untuk mengatasi keterbatasan modal dalam mengikuti perkembangan teknologi.

Selanjutnya tentang keputusan pembelian dari hasil penelitian bahwasannya meningkatkan reputasi toko merupakan faktor yang mempengaruhi keputusan pembelian. Dalam menjawab permasalahan mengenai bagaimana menciptakan sikap konsumen untuk meningkatkan minat beli yang berakhir pada keputusan pembelian, peneliti hanya memfokuskan pada tiga faktor saja yaitu pengalaman membeli, kualitas hubungan, dan reputasi toko. Bukan tidak mungkin bahwa sebenarnya masih ada faktor - faktor lain yang mungkin mempengaruhi sikap konsumen.(Dinawan, 2010). Berkaitan dengan hal tersebut diatas, maka perlu dilakukan suatu penelitian untuk menganalisis faktor-faktor yang mempengaruhi keputusan pembelian konsumen. Maka dalam penelitian ini akan dibahas mengenai.

Dengan demikian berdasarkan uraian diatas peneliti tertarik untuk meneliti tentang Analisis Marketing Mix Terhadap Keputusan Pembelian Konsumen PT. LG Elektonik Di Bandar Lampung.

\section{METODE PENELITIAN}

Metode penelitian yang digunakan dalam penelitian ini adalah deskristif kuantitatif. Dalam penelitian ini analisis yang digunakan menggunakan regresi linear sederhana.Rumus regresi linear sederhana adalah sebagai berikut :

$$
\begin{aligned}
& \mathrm{Y}=\alpha+\mathrm{bX} \\
& \text { Keterangan : } \\
& \mathrm{Y}=\text { Keputusan pembelian } \\
& \text { konsumen } \\
& \mathrm{X}=\text { Marketing MIX } \\
& \alpha=\text { Konstanta } \\
& \mathrm{b}=\text { Koefisien Regresi } \\
& \text { Pengujian hipotesisi menggunakan }
\end{aligned}
$$
koefisien determinasi digunakan untuk menghitung besarnya peranan atau pengaruh variabel bebas terhadap variabel terikat.

\section{HASIL DAN PEMBAHASAN}


Berdasarkan hasil penelitian yang dilakukan tentang analisis marketing mix terhadap keputusan pembelian adalah sebagai berikut :

\section{Analisis kualitatif}

Pada umum nya perushaan sering menghadapi permasalahan dalam melakukan kegiatan pemasaran nya, yaitu kesenjangan harapan dan kenyataan. Dalam menyusun kebijakan pemasaran digunakan analisis buruan pemasaran, yaitu yang mengkoordinasikan variabel yang terdapat dalam bauran pemasaran yang terdiri dari produk, harga, tempat, promosi, konsumen, distribusi, bukti tampilan fisik perusahaan variabel bauran ini yang dipakai oleh PT.LG elektronik cabang Lampung.

Berdasarkan kesimpulan diatas dapat disimpulkan bahwa PT. LG elektronik cabang Lampung dalam melaksakan kebijakan produk yaitu pada tipe dan jenis produk yang beragam dan kualitas yang telah teruji menjadikan PT. LG elektronik mampu bersaing dengan produk-produk pesaing yang sejenis.

Penetapan harga jual yang dilakukan PT. LG elektronik cabang Lampung adalah berdasarkan harga jual yang ditetapkan oleh kantor pusat ditambah dengan biaya pengiriman, biaya asuransi pengiriman serta margin laba.

Saluran distribusi yang digunakan PT. LG elektronik dalam menyalurkan barang dari produsen ke konsumen adalah salura distribusi eklusif. Saluran distribusi ekslusif dapat dilakukan oleh produsen dengan hanya menggunakan satu pedagang besar atau pengecer tertentu Promosi yang dilakukan PT. LG elektronik yaitu mengadakan pameran, potongan harga dan periklanan baik media cetak maupun media elektronik.

\section{Analisis kuantitatif}

Analisis data dan pengujian hipotesis dalam penelitian ini menggunakan regresi linier sederhana, untuk menguji sejauh mana pengaruh marketing mix terhadap keputusan pembelian pada konsumen PT LG. Elektronik Bandar Lampung. Pengolahan data menggunakan bantuan program SPSS versi 16.0 berdasarkan data primer yang telah diperoleh.

Tabel 1

Persamaan Regresi

\begin{tabular}{|c|c|c|c|c|c|}
\hline \multirow[t]{2}{*}{ Model } & \multicolumn{2}{|c|}{$\begin{array}{l}\text { Unstandardized } \\
\text { Coefficients }\end{array}$} & \multirow{2}{*}{$\begin{array}{c}\text { Standardized } \\
\text { Coefficients } \\
\text { Beta }\end{array}$} & \multirow[t]{2}{*}{$\mathrm{t}$} & \multirow[t]{2}{*}{ Sig. } \\
\hline & B & Std. Error & & & \\
\hline (Constant) & -26.228 & 13.018 & & -2.015 & .052 \\
\hline $\begin{array}{l}\text { Marketing Mix } \\
\text { (X) }\end{array}$ & .002 & .060 & .001 & .025 & .980 \\
\hline
\end{tabular}

Sumber: Data Primer yang diolah, 2020 
dapat diketahui hasil analisis regresi diperoleh koefisien regresi yaitu variabel $\mathrm{X}$ sebesar - 0,02 dengan konstanta sebesar 0,26,228 sehingga model persamaan regresi yang diperoleh adalah sebagai berikut:

$\mathrm{Y}=-26.228-0,02 \mathrm{X}+\mathrm{e}$

$\mathrm{Y}$ : Variabel dependen (keputusan pembelian) $\mathrm{X}$ : Marketing Mix

e : Variabel residu

Berdasarkan persamaan regresi diatas mengenai variable-variabel yang mempengaruhi keputusan pembelian, maka dapat dijelaskan sebagai berikut:

Konstanta sebesar -26.228 menyatakan bahwa jika PT.LG menggunakan variabel sebagai indikator marketing mix

Koefisien regresi variabel marketing mix.002, artinya jika jumlah produk ditambah 1 unit maka keputusan pembelian meningkat sebesar $-1,002 \%$. Dengan asumsi variabel lain dianggap konstan.

Sehingga model regresi linier sederhana dapat digunakan untuk memprediksi keputusan pembelian yang dipengaruhi oleh marketing mix.

\section{Uji Hipotesis}

Analisis linear sederhana dilakukan untuk mengetahui pengaruh masing-masing variable independen secara parsial terhadap variabel dependen.

Dari hasil perhitungan dengan menggunakan SPSS versi 16 pada tabel 4.4 dijelaskan sebagai berikut: Hipotesis :
Ho : $\beta 1=0$, artinya tidak terdapat pengaruh yang signifikan secara parsial pada masingmasing variable independen.

Ha : $\beta 1>0$, artinya terdapat pengaruh yang signifikan secara parsial pada masingmasing variable independen.

Dasar keputusan :

Apabila $\mathrm{t}$ hitung $>\mathrm{t}$ table maka Ho ditolak dan Ha diterima Apabila t hitung $<\mathrm{t}$ table maka Ho diterima dan Ha ditolak.

Nilai t tabel dengan taraf signifikasi 5\% diperoleh $\mathrm{t}(0,05)(\mathrm{n}-2)=2,021$. Dari tabel di 4.5 dapat dilihat bahwa:

Hasil perhitungan diatas menunjukkan bahwa variabel marketing mix secara signifikan berpengaruh terhadap keputusan pembelian.

Hal ini menunjukkan bahwa nilai t hitung variabel marketing mix $>t$ tabel sehingga Ho ditolak dan Ha diterima. Artinya variabel marketing mix secara parsial berpengaruh terhadap variabel dependen (keputusan pembelian).

Koefisien determinasi yang memiliki fungsi untuk menjelaskan sejauh mana kemampuan variabel independen (marketing mix) terhadap variabel dependen (keputusan pembelian)

Tabel 2

Hasil Koefisien Determinasi

Model Summary

\begin{tabular}{ccccr}
$\begin{array}{l}\text { Mod } \\
\text { el }\end{array}$ & $\mathrm{R}$ & $\begin{array}{c}\mathrm{R} \\
\text { Square }\end{array}$ & $\begin{array}{c}\text { Adjusted R } \\
\text { Square }\end{array}$ & $\begin{array}{c}\text { Std. Error of } \\
\text { the Estimate }\end{array}$ \\
1 & $.963^{\mathrm{a}}$ & .927 & .911 & .714 \\
\hline Sumber: Data Primer yang diolah, 2020 & &
\end{tabular}


Dapat diketahui bahwa nilai koefisien determinasi adalah sebesar 0,963 , ini artinya bahwa variabel keputusan pembelian dapat dijelaskan oleh variabel marketing mix sebesar 92\% sedangkan sisanya (100\% $92 \%=8 \%$ ) dijelaskan oleh variabel lain.

Pada pembahasan ini, penulis akan menjelaskan data yang telah diolah. Berdasarkan hasil uji validitas dari semua soal dalam kuesioner dinyatakan valid. Hal ini ditunjukkan dengan nilai $r$ hitung $>r$ tabel.Hasil uji reliabilitas dari semua soal diperoleh reliabilitas > 0,757 maka semua soal dalam kuesioner dinyatakan reliabel.

Uji t atau uji parsial yang telah dilakukan pada masing-masing variabel diperoleh $\mathrm{t}$ hitung variabel marketing mix $\mathrm{t}$ hitung $<\mathrm{t}$ tabel. Sehingga variabel marketing mix secara parsial berpengaruh terhadap keputusan pembelian. Uji $\mathrm{F}$ atau uji simultan pada semua variabel independen diperoleh F hitung > F tabel. Sehingga variabel variabel marketing mix secara bersama-sama berpengaruh terhadap keputusan pembelian.

\section{Pengaruh Marketing Mix Terhadap Keputusan Pembelian.}

Marketing Mix merupakan variabelvariabel yang digunakan oleh perusahaan sebagai sasaran untuk memenuhi atau melayani kebutuhan dan keinginan konsumen.variabel-variabel tersebut adalah produk, harga, promosi, tempat, konsumen, proses distribusi dan bukti tampilan fisik perusahaan.(Kusumawardani, 2011)

Bauran pemasaran menurut Kotler yang dialih bahasakan oleh Benyamin Molan (2007; 17) adalah seperangkat alat pemasaran yang digunakan oleh perusahaan untuk terus menerus mencapai tujuan pemasarannya di pasar sasaran. Dan menurut Saladin (2006; 3), bahwa bauran pemasaran (marketing mix) adalah Serangkaian dari variabel pemasaran yang dikuasai oleh pemasaran dan digunakan untuk mencapai tujuan dalam pasar sasaran. Sehingga bauran pemasaran adalah sekumpulan variabel yang terkendali.(Setiawan \& Sugiharto, 2014).

Berdasarkan uji F secara serentak variabel produk, harga, lokasi dan promosi terhadap keputusan pembelian pada konsumen Nilai $F$ tabel dengan taraf signifikasi $5 \%$ diperoleh $\mathrm{F}$ tabel sebesar 2,605.Dari tabel diatas diperoleh $\mathrm{F}$ hitung sebesar 58.305 dengan signifikasi 0,000 dibawah $0,05 \%$, ini menunjukkan $F$ hitung $(58.305)>\mathrm{F}$ tabel $(2,605)$ maka Ho ditolak dan Ha diterima. Artinya variabel produk,harga lokasi, promosi, konsumen, proses dan tampilan secara bersama-sama berpengaruh terhadap variabel independen (keputusan pembelian).

Nilai koefisien determinasi $r^{2}$ adalah sebesar 0,963, ini artinya bahwa variabel keputusan pembelian dapat dijelaskan oleh variabel marketing mix sebesar $92 \%$ sedangkan sisanya $(100 \%$ $92 \%=8 \%)$ dijelaskan oleh variabel lain.

Hal ini sejalan dengan penelitian hasil penelitian yang diperoleh setelah dilakukan pengujian terhadap 100 orang responden yang merupakan pembeli atau pelanggan dari Azzwar Parfum Lubeg padang maka dapat disimpulkan bahwa Marketing Mix berpengaruh signifikan terhadap keputusan pembelian parfum di Azzwar Parfum Lubeg Padang karena memiliki $\mathrm{F}$ - hitung $>$ dari $\mathrm{F}$ - tabel yaitu sebesar 9,562. Hal ini membuktikan bahwa bauran pemasaran mempengaruhi keputusan pembelian produk parfum di Azzwar Parfum(Andika \& Susanti, 2018)

Dengan demikian marketing mix berpengaruh terhadap keputusan pembelian. 


\section{KESIMPULAN}

Dengan melihat hasil penelitian yang telah dibahas, maka dapat ditarik kesimpulan: Berdasarkan uji $\mathrm{F}$ secara serentak variabel marketing mix terhadap keputusan pembelian pada konsumen Nilai $\mathrm{F}$ tabel dengan taraf signifikasi 5\% diperoleh $\mathrm{F}$ tabel sebesar 2,605.Dari tabel diatas diperoleh $\mathrm{F}$ hitung sebesar $\quad 58.305$ dengan signifikasi 0,000 dibawah $0,05 \%$, ini menunjukkan F hitung (58.305) $>\mathrm{F}$ tabel $(2,605)$ maka Ho ditolak dan Ha diterima. Artinya variabel marketing mix secara bersama-sama berpengaruh terhadap variabel independen (keputusan pembelian).

Nilai koefisien determinasi $\mathrm{r}^{2}$ adalah sebesar 0,963 , ini artinya bahwa variabel keputusan pembelian dapat dijelaskan oleh marketing mix sebesar 92\% sedangkan sisanya $(100 \%-92 \%=8 \%)$ dijelaskan oleh variabel lain. Hal ini dilihat dalam analisis linear sederhana yang telah dilakukan menunjukkan nilai y diperoleh $(19,503)$.

\section{UCAPAN TERIMAKASIH}

Terimakasih kepada Universitas Sang Bumi Ruwa Jurai yang telah berkontribusi dalam penelitian ini

\section{DAFTAR PUSTAKA}

Andika, A., \& Susanti, F. (2018). PENGARUH MARKETING MIX TERHADAP KEPUTUSAN PEMBELIAN PARFUM DI AZZWARS PARFUM LUBEG $P A D A N G$ [Preprint]. INA-Rxiv. https://doi.org/10.31227/osf.io/upgc 3
Dinawan, M. R. (2010). ANALISIS FAKTOR - FAKTOR YANG MEMPENGARUHI KEPUTUSAN PEMBELIAN (Studi kasus pada konsumen Yamaha Mio PT Harpindo Jaya Semarang). JURNAL SAINS PEMASARAN INDONESIA, Volume IX, No. 3.

Harahap, D. A. (2017). Analisis FaktorFaktor Yang Mempengaruhi Keputusan Pembelian Konsumen di Pajak USU (Pajus) Medan [Preprint]. INA-Rxiv. https://doi.org/10.31227/osf.io/2dg3 q

Kusumawardani, D. A. (2011). STUDI MENGENAI KEPUTUSAN PEMBELIAN JASA WEDDING AND EVENT ORGANIZER. Universitas Diponegoro, 52.

Ledy, D. S., Haryono, D., \& Situmorang, S. (2019). ANALISIS BAURAN PEMASARAN (MARKETING MIX) DAN STRATEGI PENGEMBANGAN (STUDI KASUS PADA AGROINDUSTRI KOPI BUBUK CAP INTAN DI KOTA BANDAR LAMPUNG). Jurnal Ilmu-Ilmu Agribisnis, 7(1), 52.

https://doi.org/10.23960/jiia.v7i1.52 $-59$

Nofri, O., \& Hafifah, A. (2018). ANALISIS PERILAKU KONSUMEN DALAM MELAKUKAN ONLINE SHOPPING DI KOTA MAKASSAR. Jurnal Minds: Manajemen Ide dan Inspirasi, 5(1), 113-132.

https://doi.org/10.24252/minds.v5i1. 5054

Poluan, F. M. A., Mandey, S. L., \& Ogi, I. W. J. (2019). STRATEGI 


\begin{tabular}{lrr} 
MARKETING & MIX & DALAM \\
MENINGKATKAN & VOLUME \\
PENJUALAN & (STUDI & PADA \\
MINUMAN & \multicolumn{2}{c}{ KESEHATAN } \\
INSTANT ALVERO). Jurnal \\
EMBA, Vol 7. No 3, 10.
\end{tabular}

Setiawan, W., \& Sugiharto, S. (2014). PENGARUH MARKETING MIX TERHADAP KEPUTUSAN PEMBELIAN TOYOTA AVANZA
TIPE G DI SURABAYA. Jurnal Manajeman Pemasaran, Vol. 2 No. 1 . 